\title{
Performance audit in the vision of public sector management. The case of Romania
}

\author{
Aurelia Ștefănescu ${ }^{1, a}$ and Cristina-Petrina Trincu-Drăgușin ${ }^{\mathrm{a}}$ \\ ${ }^{\text {a }}$ The Bucharest University of Economic Studies, Romania
}

\begin{abstract}
Research Question: What is the impact of the performance audit missions on the activity of the Romanian public institutions?

Motivation: Public resources' management and use, public sector entities' performance, in the context of the economic environment turbulences and of the complexity and heterogeneity of the public services demand are of interest to a wide range of interested parties. Thus, the informational valences of the performance audit represent for the public sector management, a credible and relevant information source to substantiate the decisionmaking process focused on performance and circumscribed to the community members.

Idea: The paper includes an empirical research on the investigation of the public sector management perception regarding the impact of the performance audit missions performed by the Romanian Court of Accounts, on the public institutions activity.

Data: Information regarding the performed missions and the entities subject to performance audit was collected by reviewing the Romanian Court of Accounts' portfolio of publications (available online on the institution's official website). The email addresses of the respondents were collected by consulting the official web pages of the audited entities (contact section). Tools: The research is based on the study of the public sector management's perception regarding the performance audit missions performed by the Romanian Court of Accounts. In this regard, we developed and disseminated questionnaires to the management of public sector entities subject to performance audit within the period 2015-2019. Complementarily, in order to identify the tendencies and the respondents' homogeneous perceptions, the descriptive analysis is completed by cluster analysis and multidimensional scaling. Data processing, clustering and the results' analysis were performed using the SPSS statistical software.

Findings: The research results show that performance auditing contributes to improving the economicity, efficiency and effectiveness in the public resources use, but its usefulness is inversely proportional to the professional experience of the respondents within the audited

${ }^{1}$ Corresponding author: Aurelia Ștefănescu, The Bucharest University of Economic Studies, Faculty of Accounting and Management Information Systems, Professor PhD, 6 Piața Romană, 1st District, Bucharest, 010374, Romania, email address: aurelia.stefanescu@cig.ase.ro.
\end{abstract}


entity. The respondents also consider that the performance audits' objectives are appropriate to the sensitive areas related to the activity of public institutions, and their results provide a fair image regarding the public resources' management and use. Concerning the performance audit reports, the respondents consider them objective, rigorous, credible, and the collaboration and communication of the auditors with the entity are appreciated as successful elements of the performance audit missions.

Contribution: The paper adds value to the specialized literature, given that the performance audit issue in the vision of the public sector management has not been addressed in Romania, being also limited internationally. The research results are also of interest to both the professional and the socio-economic environment, concerned with the public sector entities performance.

Keywords: performance audit, public sector, interested parties, supreme audit institution, Romania, Court of Accounts.

\section{JEL codes: $\mathrm{M} 42, \mathrm{C} 38, \mathrm{H} 83$}

\section{Introduction}

By its nature, the public sector functioning mechanism is based on the interrelated relationship: public resources, performance, public services, sustainability, transparency, interested parties. From this perspective, an important role in building and maintaining this interrelated relationship lies with the performance audit. The performance audit is a component of the external public audit performed by the Romanian Court of Accounts (abbreviated RCoA). The latter is a valuable activity for a wide variety of users, being an integrative approach, involving both internal issues specific to the Romanian supreme audit institution and to the audited entities, and external issues specific to the interested parties in the findings, conclusions and recommendations of the related missions.

The changes in the public sector, generated by the philosophy of the new public management implementation, had an impact also on the way of approaching the external public audit. The new public management has determined a new paradigm in the public sector, introducing new roles oriented on the transparent governance, with focus on results and performance (Matei, 2006). From another perspective, Bartoli (2009) integrates in the definition of the new public management, the following components: the efficiency, the decentralization, the management of change and the public service' particularity. In the context in which public management's main objective is satisfying general and specific public interests belonging to consumers of public products and services (Androniceanu, 2008), we consider innovative and useful to investigate the perception of public sector management on the impact of performance audit missions performed by RCoA, in 
order to analyze the extent to which they promote and produce change within the audited entities.

In relation to the new public management, we consider that in approaching the specific public audit activity, the issue of the main interested parties is of significant importance. In this respect, the interested parties integrate two components, namely internal and external. In the category of the internal interested parties, involved in the performance audit activity, there are on the one hand the professionals of the supreme audit institution (the external public auditors, the management of the specialized structures within RCoA) and on the other hand the professionals from audited entities (public management and executive staff). The external parties, interested in the results of the external public audit activity, are the Parliament, the Government, the deliberative public authorities of territorial administrative units, the citizens, the media or the general public, but also other interested parties (Figure 1).

Figure 1. The typology of the interested parties in the external public audit activity

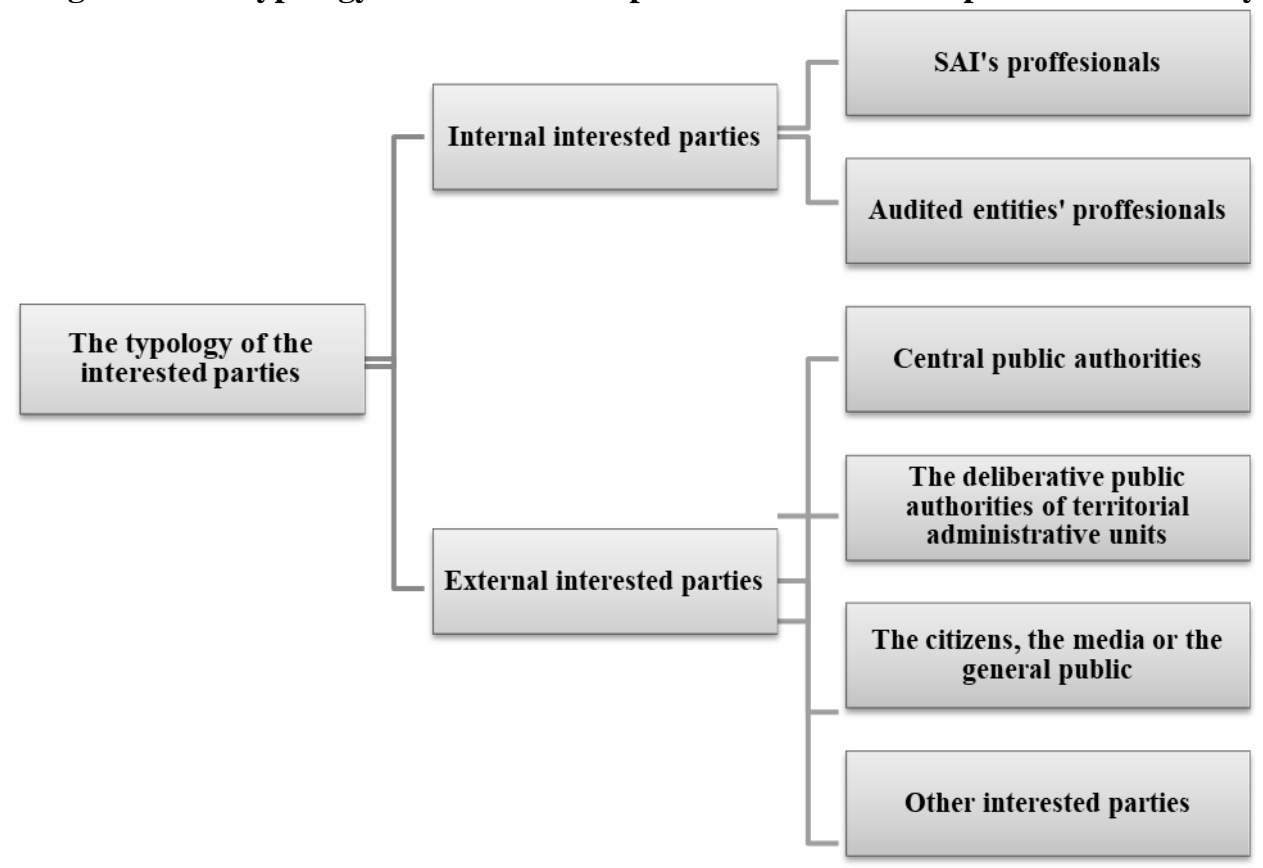

Within the portfolio of interested parties, an apart category is represented by the public managers, who present interest in performance auditing in a dual manner, as internal stakeholders (as professionals and responsible parties within the audited entities), but also external interested parties of the audited entities. The premise of the research is the importance of the performance audit, as an activity that supreme audit institutions (abbreviated SAIs) carry out at the entities in their area of competence, in order to contribute, through the recommendations made in the 
specific reports, to improving the economicity, the efficiency and the effectiveness of their activities.

In Romania, the performance audit has a short history of just over a decade. The concept was explicitly legislated in 2008, when RCoA's activity was divided into three levels, specific to the supreme audit institutions, namely control, financial audit and performance audit (Bostan \& Dascălu, 2016). The fairly recent regulation of the performance audit is the consequence of Romania's integration as a full member of the European Union. From this perspective, Romania has developed a regulatory framework oriented towards performance, sustainability and transparency in the public sector.

As Tiron-Tudor (2007) points out, the adoption of performance audit in the public sector is one of the most significant new additions to the audit's traditional role. This new type of audit has evolved mainly to meet the citizens' and the Parliament's need for more information regarding the " $3 \mathrm{E}$ " in the resources' use by the public managers acting on behalf of the executive.

According to national regulations in the field (the organic law of the Court of Accounts and the Regulation regarding the organization and conduct of its specific activities), the performance audit is the independent assessment of how an entity, program/project/process, activity or operation works in terms of the 3E (efficiency, effectiveness and economicity). In this sense, economicity reflects the cost of the allocated resources in order to achieve the estimated results of an activity, while maintaining the appropriate quality of these results. The efficiency highlights the maximization of the results of an activity in relation to the used resources and the effectiveness, the fulfillment degree of the objectives programmed for each of the activities and the relationship between the projected effect and the actual result of that activity.

From the perspective of the International Standards of Supreme Audit Institutions, the performance audit focuses on determining whether the operations, the programs and the institutions operate in accordance with the principles of economicity, efficiency and effectiveness and whether there is room for improvement. Within these missions, the performance is evaluated in relation to certain criteria, the causes of deviations from them or other problems being analyzed. The purpose of this form of audit is to answer the audit questions and to issue recommendations for improving the pursued issues (Trincu-Drăgușin \& Ștefănescu, 2020).

The paper is structured in the following sections: literature review, empirical research regarding the investigation of the public management perception on the impact of the performance audits performed by RCoA and includes a description of the research methodology and the research results. The last section is dedicated to conclusions, limits and future research directions. 


\section{Literature review}

The approach on the aspects regarding the performance audit in the public sector was in line with the objectives of the research carried out at the level of the specialized literature, although limited both nationally and interationally.

The paramount role of supreme audit institutions in insuring the public sector accountability is already known, being corellated with the public value delivered, through their specific activities, to the Parliament, the citizens and other internal and external interested parties (Cordery \& Hay, 2019).

The new public management paradigm has facilitated worldwide the development of the public sector audit activities. Nonetheless, SAIs differ significantly, with respect to their structure, the results of their activities in relation with the stakeholders and their impact on entities and the contemporaneous society (Johnsen, 2019).

The performance audit is one of the activities that SAIs carry out in order to ensure the public funds' economic, effective and efficient use (Umor et al., 2018). According to Sembiyeva et al. (2019), the main difference between the performance audit and any review activity consists in the fact that the first one must exceed the traditional audit report. As Svardsten (2019) points out, the performance audit, as a specific demarche of the external public audit conducted by SAIs, is a practice with a high degree of democratic relevance since it focuses on transparency and on the evaluation of the public sector performance. The public sector performance audit holds a significant role in government accountability evaluation, by monitoring the functioning of the public power and, distinctly, the public resources utilization. Subsequent to the performance audit missions, the follow-up activities dedicated to monitoring the implementation of the recommendations related to the audit findings are particularly important. The lack of such monitoring is likely to influence both the performance audit added value' assesement and the expected results of the audit recommendations (Umor et al., 2016).

The research of the value added by the performance audit missions conducted by the public external auditors of RCoA is closely related to the analysis of supreme audit institutions' results measurement framework. The importance of supreme audit institutions' results measurement is acknowledged in the relevant literature, which also debates paths to its improvement, but, as Johnsen (2019) underscores, there is limited published literature outside the Anglo-american and north-european context. The research regarding the way of measuring the supreme audit institutions results has focused mainly on performance auditing and, to a lesser extent, on other types of external public audit, and the researchers have used descriptive indicators more frequently than quantitative indicators (Bonollo, 2019). Slobodyanik (2019) considers that SAIs are capable of augumenting the state's administrative structures' responsibility towards society, both regarding the used resources and the performance related results. 
Yetano et al. (2019) analyzed the perception of Latin American public entities regarding the effectiveness of performance audits conducted on them by their SAIs, in order to determine the extent to which these audits generate institutional changes. The results of their research indicate different degrees of implementation for the performance audit in these countries, concurrently highlighting the correlation between the perceived utility of the performance audits, the confidence placed in the SAIs' activities and the implementation of the audit recommendations respectively. From a similar perspective, Torres et al. (2019) analyzed the utility of performance audits conducted by the EU SAIs. Aiming to evaluate the performance audits' impact, they followed the degree of implementation of the audit recommendations and their research highlighted two significant manners in which the performance audit recommendations generate impact: the Anglo-american model, based on the audited entities' actions and on the follow-up proceedings and the German model, based on the parliamentarian reaction.

Employing polling technique and the regression analysis, Johnsen et al. (2019) studied the impact of the performance audit conducted on public administration in four north-european countries (Denmark, Finland, Norway and Sweden). The research indicates that the audited entities have a positive perception of these initiatives on utility, changes, improvements and, in some measure, on responsibility. Moreover, they underline that some factors that previous research found important to performance audit impact in some countries, were perceived as insignificant to all of the four Nordic countries, but that SAIs' legitimacy, the audit quality and the consequences of media attention were deemed important factors.

Using polling technique, Reichborn-Kjennerud and Johnsen (2018) examined the audited entities' inclination to implement changes following the performance audits conducted by Norway's supreme audit institution. The study results showed a tendency to operate changes, but the institutional, political and instrumental factors have some impact on this propensity for change. Previously, exploring the impact of performance audit on public policy, Reichborn-Kjennerud (2014) showed that Norway's supreme audit institution is mainly concerned with managerial issues and that most of the performance audit reports enjoy only a moderate interest from massmedia and the parliamentary control commission.

Analyzing the impact of the performance audits on the Estonian public entities, Raudla et al. (2016) showed that these activities are perceived as useful, even though not leading to specific changes to organizational policy and procedures and that the performance audit recommendations are more likely to be implemented when parliament members pay attention to this form of audit and when mass-media attention leads to political debates. From a similar perspective, a study on the impact of performance audits on Belgian administration (Desmedt et al., 2017) showed that these actions did not determine radical changes in the entities' organizational life, but the auditors' intervention was nonetheless visible, the nature of the impact being conceptual rather than strategic or instrumental. 
Through a survey conducted on 96 representatives of public entities, Alwardat and Basheikh (2017) analyzed the performance audits' impact on the public administration in Saudi Arabia. They assessed the extent to which the auditors' efforts impacted on the public management in Saudi institutions, in order to improve the use of public resources. The results of their research show that the SAI can claim remarkable achievements regarding the performance audits' impact on Saudi public entities. Regardless of their experience and qualifications, the public entitites' representatives showed positive perceptions of the performance audit process, being convinced of the usefulness and quality of the SAI's audit reports. At the same time, the results revealed that, through its efforts, the SAI contributed to the multilateral support of public management for defining priorities, adopting strategic and operational plans, evaluating projects and services, identifying problems and formulating valuable recommendations.

In Romania, the perspective of the public management regarding the SAI's performance audit impact has not been addressed so far, given the fact that public external audit, in general, and performance audit, in particular, are limited research topics. The main approaches in the national literature focused on performance auditing in the entities of the public sector as a new challenge for Eastern European countries (Tiron-Tudor, 2007), on the parallels between performance and financial audits (Nișulescu \& Martin David, 2009), on the analysis of performance audit' contribution in mitigating the effects of the financial crisis (Ștefan \& Păunică, 2014), on the correlation between the volume of activity of the audited entities and the errors that distort the fair image of the financial statements (Pitulice \& Ștefãnescu, 2016), on the principles and ethical values in the specific activity of external public audit (Marcu, 2018), on the external public audit typology (Trincu-Drăgușin \& Ștefănescu, 2020). In this context, the results of the research carried out in this paper will add value to the specialized literature regarding the performance audit approach in public institutions, in general, and particularly they will also open some innovative research directions for the Romanian literature.

\section{Empirical research on public sector management's opinion regarding the impact of the performance audits conducted by the Romanian Court of Accounts}

\subsection{The research methodology}

The research conducted aimed to investigate the opinion of the Romanian public institutions' management regarding the impact of the performance audit missions conducted by the Romanian Court of Accounts, as supreme audit institution, on their activity. With this purpose, we used a quantitative scientific research methodology. Thus, we developed a questionnaire, which was disseminated to the entities' management (legal representatives and/or managers of the financial-accounting departments) where the Romanian Court of Accounts conducted performance audits between 2015 and 2019. 
The relevant information pertaining to the conducted audits and the audited entities was collected by reviewing the RCoA's publications portfolio (available online on RCoA's website, www.curteadeconturi.ro). Within the research horizon (20152019), RCoA's proffessionals conducted 730 performance audits, on 644 public entities in their field of competence, pertaining to various domains of the public sector: administration, healthcare, education, research, environment, sports, infrastructure, transport, culture, public finance, public utilities, health insurance, social welfare, communications, postal service, social security, regional development. Subsequent to identifying the audited entities in the research period, the respondents' contact information (the institutional email addresses) was collected by consulting the entities' official webpages (contact section).

The survey, comprised of 24 questions, was formatted and disseminated using Google Forms, and respondents' confidentiality was guaranteed. The questionnaire was disseminated to the management of the 644 entities, at the level of which RCoA's structures conducted performance audit missions. The questionnaire was disseminated and the responses were collected during March - April 2020 and 74 valid responses were obtained. The responses were collected and centralized using Google Forms. Subsequently, the collected data and information were processed and analyzed used SPSS statistical software. In order to identify the public management's consistent perceptions on RCoA's performance audit impact, the descriptive analysis was doubled by cluster and MDS (Multidimensional Scaling) analysis. By adapting the vision of Yetano et al. (2019), these techniques allowed for graphic illustration of the characteristics, by grouping respondents that show similar behaviour. Cluster analysis took into account the responses classification in several major groups, in order to identify each group's tendencies. Cluster analysis revealed, for example, legal representatives' perception on RCoA's performance audits, based on their level of work experience inside the audited entities.

\subsection{The research results}

The collected answers' analysis higlights the fact that, although the respondents are different in relation to their identification variables (gender, field of study, work experience within the entity), a series of convergent perception tendencies were identified regarding certain analysed aspects.

The analysis of the respondents' general coordinates (Table 1) highlights the fact that $60.81 \%$ are women and $39.19 \%$ are men. If we refer to the field of study, the respondents' structure is revealed as diverse, the questionnaire being filled by graduates of: public administration, aviation, chemistry, construction, law, economics, physical education, geography, information technology, engineering, history, medicine and environmental studies. Most respondents have an Economics degree $(64.86 \%)$, followed by Engineering (9.47\%) and Law (8.12\%). From another standpoint, most respondents represent entities audited in 2019 (66\%), while 18\% 
hail from entities audited in 2018, 12\% in 2017 and only 4\% in between 2015 and 2016.

Table 1. The respondents' general coordinates

\begin{tabular}{ccc}
\hline Gender & Women & $60.81 \%$ \\
& Men & $39.19 \%$ \\
& Public administration & $1.35 \%$ \\
& Aviation & $1.35 \%$ \\
& Chemistry & $1.35 \%$ \\
& Construction & $1.35 \%$ \\
Field of study & Law & $8.12 \%$ \\
& Economics & $64.86 \%$ \\
& Physical Education & $2.70 \%$ \\
& Geography & $1.35 \%$ \\
& Information & $2.70 \%$ \\
& Technology & $9.47 \%$ \\
& Engineering & $1.35 \%$ \\
& History & $2.70 \%$ \\
& Medicine & $1.35 \%$ \\
& Environmental studies & $66 \%$ \\
& 2019 & $18 \%$ \\
at the entity & 2018 & $12 \%$ \\
& 2017 & $4 \%$ \\
\hline
\end{tabular}

Figure 2 presents the classification tree (the dendrogram) made using Ward's hierarchical grouping method. The dendrogram resulting from the cluster analysis facilitated the configuration of four groups or major classes of respondents.

Figure 2. The classification dendrogram using Ward method

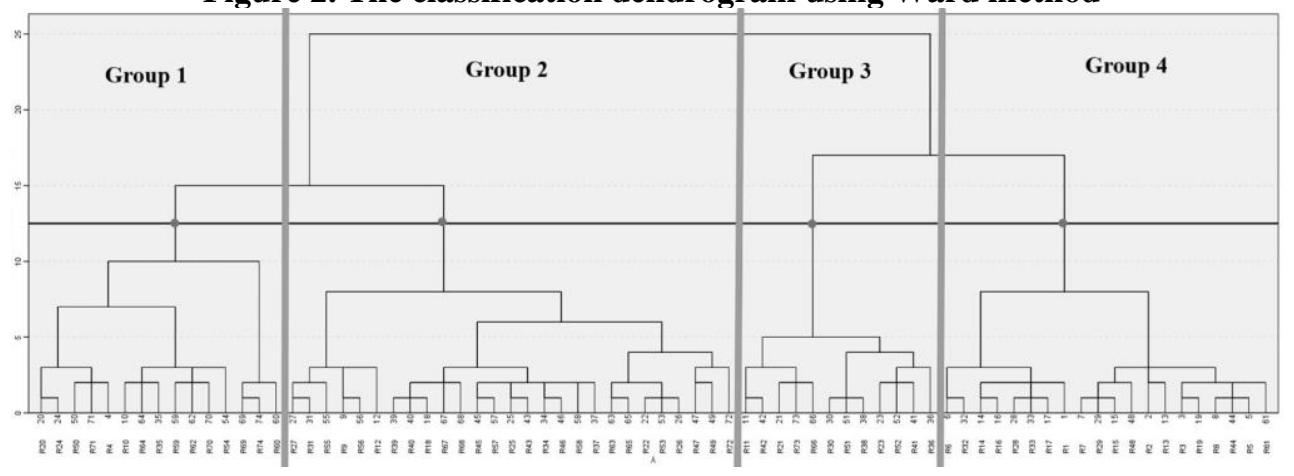

The hierachical classification method was used in order to identify the number of groups to be considered, but for allocating each respondent to such a group, the Kmeans algorithm was used. 
The variables considered for clustering are presented in Table 2 . The use of the Kmeans algorithm was preceded by the normalization of the values associated with the variables, using the $\mathrm{Z}$ score.

Table 2. The variables presentation

\begin{tabular}{|c|c|}
\hline Questions & Variables \\
\hline $\mathrm{Q} 1$ & Gender \\
\hline Q4 & Respondents' experience within the entity \\
\hline Q5 & The year of RCoA's last performance audit at the entity \\
\hline Q6 & The usefulness of RCoA's performance audits \\
\hline Q7 & $\begin{array}{l}\text { The extent to which the performance audit missions add value in increasing } \\
\text { the economicity, efficiency and effectiveness within the activity of the } \\
\text { public sector entities }\end{array}$ \\
\hline Q8 & $\begin{array}{l}\text { The adequacy of the performance audit theme and objectives in relation with } \\
\text { the fundamental aspects of the entity's activity }\end{array}$ \\
\hline Q9 & $\begin{array}{l}\text { The appropriate assessment of the economicity, efficiency and effectiveness } \\
\text { with which the public resources are managed in order to achieve the set } \\
\text { objectives }\end{array}$ \\
\hline Q10 & $\begin{array}{l}\text { The audit's predominant focus on error identification and/or on the } \\
\text { performance evaluation according to certain viable landmarks }\end{array}$ \\
\hline Q11 & $\begin{array}{l}\text { Public external auditors' approach during performance audit, compared to } \\
\text { financial or compliance audit }\end{array}$ \\
\hline Q12 & $\begin{array}{l}\text { The auditors' relation with the auditee's personnel compared to that } \\
\text { perceived during financial or compliance audits }\end{array}$ \\
\hline Q13 & $\begin{array}{l}\text { The respondents' involvement in the process of identifying the best ways } \\
\text { (recommendations) for improving the activity }\end{array}$ \\
\hline Q15 & $\begin{array}{l}\text { The extent to which changes were recommended after the performance } \\
\text { audits }\end{array}$ \\
\hline Q16 & $\begin{array}{l}\text { The extent to which the performance audits have led to the improvement of } \\
\text { the management policies and practices, of the internal management control } \\
\text { systems, of the accountability in the economical, effective and efficient use } \\
\text { of the public funds, of the internal mechanisms of monitoring and assessing } \\
\text { performance, of the transparency regarding how to manage public funds and } \\
\text { the accuracy of the financial-accounting activity, of the transparency } \\
\text { regarding the management of public funds and the accuracy of the financial- } \\
\text { accounting activity }\end{array}$ \\
\hline Q18 & $\begin{array}{l}\text { The extent to which the stakeholders' perception has changed as a result of } \\
\text { the performance audit report publication }\end{array}$ \\
\hline Q19 & $\begin{array}{l}\text { The extent to which the entity has implemented the recommendations made } \\
\text { by the SAI professionals after the undertaken performance audit missions }\end{array}$ \\
\hline Q20 & $\begin{array}{l}\text { The extent to which the SAI professionals also carried out follow-ups } \\
\text { regarding the recommendations implementation }\end{array}$ \\
\hline Q22 & $\begin{array}{l}\text { The extent to which the recommendations have contributed to the increase } \\
\text { of the economicity, efficiency and effectiveness of the public funds use at } \\
\text { the entity level }\end{array}$ \\
\hline
\end{tabular}

Cluster and MDS analysis results are shown in Figure 3, which graphically reflects the 4 major groups identified. 


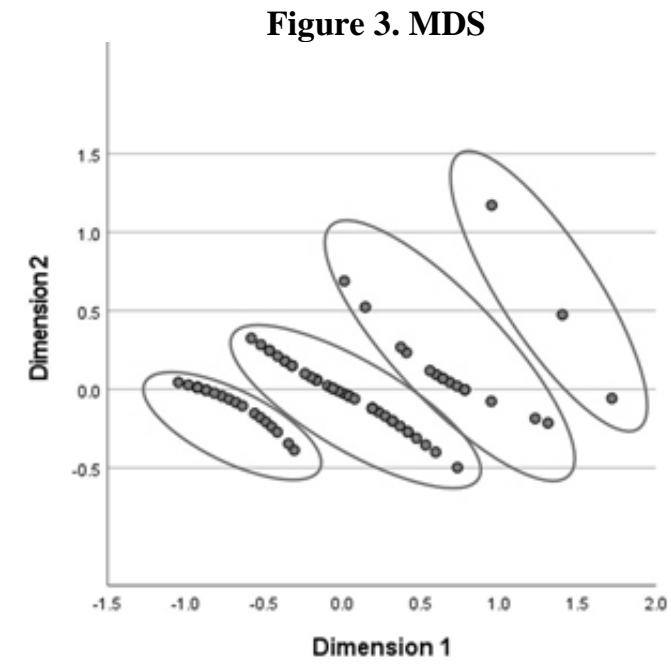

The differences between clusters (the clusters complementarity) are reflected through Figure 4.

Figure 4. The clusters complementarity

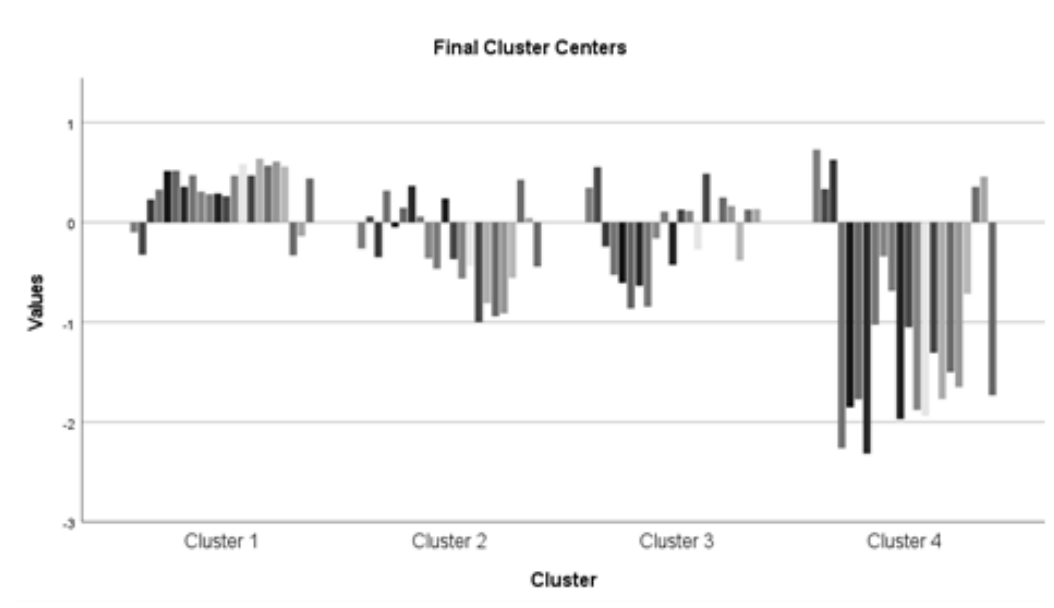

The clustering statistical significance was assessed using the ANOVA table (Figure 5), showing:

- important significance for the repondents' work experience within the entity, performance audits' utility, the extent to which they add value in increasing the economicity, efficiency and effectiveness within the activity of the public sector entities, the adequacy of the performance audit theme and objectives in relation with the fundamental aspects of the entity's activity, the appropriate assessment of the economicity, efficiency and effectiveness with which the public resources are managed in order to achieve the set objectives, the audit's predominant focus on 
error identification and/or on the performance evaluation according to certain viable landmarks, the auditors' relation with the auditee's personnel compared to that perceived during financial or compliance audits, the respondents' involvement in the process of identifying the best ways (recommendations) for improving the activity, the extent to which changes were recommended after the performance audits, the extent to which the performance audits have led to the improvement of the management policies and practices, of the internal management control systems, of the accountability in the economical, effective and efficient use of the public funds, of the internal mechanisms of monitoring and assessing performance, of the transparency regarding how to manage public funds and the accuracy of the financial-accounting activity, of the transparency regarding the management of public funds and the accuracy of the financial-accounting activity, the extent to which the stakeholders' perception has changed as a result of the performance audit report publication, the extent to which the entity has implemented the recommendations made by the SAI professionals after the undertaken performance audit missions, the extent to which the recommendations have contributed to the increase of the economicity, efficiency and effectiveness of the public funds use at the entity level;

- relative significance for gender, the year of RCoA's last performance audit at the entity, public external auditors' approach during performance audit, compared to financial or compliance audit;

- reduced significance for the extent to which the SAI professionals also carried out follow-ups regarding the recommendations implementation; in other words, this variable has no impact on clustering.

Figure 5. The statistical significance of clustering (the ANOVA table)

\begin{tabular}{|c|c|c|c|c|c|c|}
\hline \multicolumn{7}{|c|}{ ANOVA } \\
\hline & \multicolumn{2}{|c|}{ Cluster } & \multicolumn{2}{|c|}{ Error } & \multirow[b]{2}{*}{$\mathrm{F}$} & \multirow[b]{2}{*}{ Sig. } \\
\hline & Mean Square & df & Mean Square & df & & \\
\hline Zscore(Q1) & 1.901 & 3 & .961 & 70 & 1.977 & .125 \\
\hline Zscore(Q4) & 3.037 & 3 & .913 & 70 & 3.327 & .024 \\
\hline Zscore(0.5) & 2.222 & 3 & .948 & 70 & 2.345 & .080 \\
\hline Zscore(06) & 10.185 & 3 & .606 & 70 & 16.796 & .000 \\
\hline Zscore(Q7) & 9.653 & 3 & .629 & 70 & 15.342 & .000 \\
\hline Zscore (Q8) & 11.409 & 3 & .554 & 70 & 20.598 & .000 \\
\hline Zscore(Q9) & 11.643 & 3 & .544 & 70 & 21.408 & .000 \\
\hline Zscore(Q10) & 7.839 & 3 & .707 & 70 & 11.088 & .000 \\
\hline Zscore(Q11) & 2.227 & 3 & .947 & 70 & 2.351 & .080 \\
\hline Zscore(Q12) & 2.988 & 3 & .915 & 70 & 3.266 & .026 \\
\hline Zscore(Q13) & 7.482 & 3 & .722 & 70 & 10.359 & .000 \\
\hline Zscore(Q15) & 3.228 & 3 & .905 & 70 & 3.569 & .018 \\
\hline Zscore: $016-1$ & 9.350 & 3 & .642 & 70 & 14.561 & .000 \\
\hline Zscore: Q16-2 & 10.583 & 3 & .589 & 70 & 17.959 & .000 \\
\hline Zscore: Q16-3 & 12.442 & 3 & .510 & 70 & 24.413 & .000 \\
\hline Zscore: Q16-4 & 13.090 & 3 & .482 & 70 & 27.165 & .000 \\
\hline Zscore: Q16-5 & 12.722 & 3 & .498 & 70 & 25.566 & .000 \\
\hline Zscore: $016-6$ & 13.377 & 3 & .470 & 70 & 28.490 & .000 \\
\hline Zscore(Q18) & 7.064 & 3 & .740 & 70 & 9.545 & .000 \\
\hline Zscore(Q19) & 2.680 & 3 & .928 & 70 & 2.888 & .042 \\
\hline Zscore(Q20) & .610 & 3 & 1.017 & 70 & .600 & .617 \\
\hline Zscore(Q22) & 7.485 & 3 & .722 & 70 & 10.366 & .000 \\
\hline
\end{tabular}

Vol. 19, No. 4 
Cluster 1 represents $47 \%$ of the total respondents. They have an average of 11 years of experience in the entities they represent; $74 \%$ of them give high utility to performance audits; they consider that the performance audit missions add, to a great or a very large extent, value for the economicity, efficiency and effectiveness increase in the activity of the public sector entities; most of them consider that the themes and the objectives of the performance audits are appropriate to the most important aspects of the entities' activity and that the auditors properly assessed the factual situation and gave a fair image of the economicity, efficiency and effectiveness with which the public resources are managed in order to achieve the set objectives; more than half believe that the performance audit was equally focused on identifying errors and evaluating performance, and $37 \%$ believe that the audit was focused more on evaluating performance; regarding the approach adopted by external public auditors in performance auditing compared to financial or compliance audit, $51 \%$ consider it to be relatively different and $34 \%$ significantly different; $46 \%$ believe that the relationship between the auditors and the audited entity staff was felt to be different, perhaps more collegial, in the case of the performance audit than in the case of the financial or the compliance audit; most of them declared they were involved in identifying the best ways to improve their activity; $80 \%$ stated that, following the audits, changes were recommended at the level of the entities they represent $(64 \%$ stated that the recommended changes were not significant); from the perspective of the majority of respondents, the performance audits have largely led to the improvement of the management policies and practices, the managerial internal control systems, the accountability in the economic, effective and efficient use of the public funds, the own mechanisms for monitoring and evaluating performance, the transparency regarding the way of managing public funds and of the financial-accounting activity accuracy; 34\% declared that the stakeholders perception changed as a result of the performance audit report publication; half of them stated that the recommendations had been partially implemented; in most cases, the SAI professionals also carried out actions for monitoring the recommendations implementation; according to most respondents, the recommendations made following the performance audit missions have contributed a lot in terms of increasing the economicity, efficiency and effectiveness in the public funds use at the entity level.

Cluster 2 groups $26 \%$ of the total respondents. They have an average of 15 years of experience in the entities they represent; $74 \%$ of them consider that the usefulness of the performance audits is high and over $63 \%$ consider that these missions bring, to a large extent, added value in order to increase the economicity, the efficiency and the effectiveness in the public sector entities activity; $68 \%$ of them consider that the performance audits themes and objectives are appropriate to the most important aspects of the entities activity and 95\% of them believe that the auditors properly assessed the factual situation and gave a fair image of the economicity, efficiency and effectiveness with which the public resources are managed in order to achieve the set objectives; $68 \%$ consider that the performance audit was equally oriented 
towards the errors identification and the performance evaluation; regarding the approach adopted by the external public auditors in performance auditing compared to financial or compliance auditing, 53\% consider it to be relatively different, while $37 \%$ consider that it was not different; $90 \%$ of them stated that the relationship between the auditors and the audited entity staff was not felt to be different in the performance audit case compared to the financial or the compliance audit and that they were involved in the process of identifying the best ways to improve the activity; 68\% stated that, following the performance audits, changes were recommended at the level of the entities they represent, but these changes were not significant; from the perspective of most respondents, the performance audits have relatively improved the management policies and practices, the management internal control systems, the accountability in the economic, effective and efficient use of the public funds, the own mechanisms for monitoring and evaluating performance, the transparency regarding the way of managing public funds and the financialaccounting activity accuracy; 74\% stated that stakeholders' perception did not change as a result of the performance audit report publication; most stated that the recommendations were fully implemented, contributing relatively to increasing the economicity, efficiency and effectiveness in the use of public funds at the level of the entity and that the SAI professionals also carried out actions for monitoring the recommendations implementation.

Cluster 3 includes $22 \%$ of the total respondents. They have an average experience of 19 years in the entities they represent; $75 \%$ of them consider that the performance audits have medium utility; half consider that these missions bring relatively added value for increasing the economicity, the efficiency and the effectiveness in the activity of public sector entities; $69 \%$ consider that the themes and the objectives of the performance audits are relatively appropriate to the most important aspects of the entities' activity; half of them believe that the auditors properly assessed the factual situation and gave a fair image of the economicity, the efficiency and the effectiveness with which the public resources are managed in order to achieve the set objectives; $63 \%$ consider that the performance audit was mainly focused on identifying errors and that the approach adopted by the external public auditors in these missions was relatively different from the approach in the financial or the compliance audits, but the relationship between the auditors and the audited entity staff was not felt to be different; over $60 \%$ said they were involved in identifying the best ways to improve their activity; $75 \%$ stated that, following the performance audits, changes were recommended at the level of the entities they represent, but these change were not significant; in their opinion, the performance audits have determined, to a large extent, the improvement of the management policies and practices, the management internal control systems, the accountability in the economic, effective and efficient use of the public funds, the transparency regarding the way of managing public funds and the financial-accounting activity accuracy and relatively the improvement of the own mechanisms for monitoring and evaluating performance; half stated that the stakeholders perceptions had changed as a result of the performance audit report publication; the majority stated that the 
recommendations made were fully implemented, contributing relatively to increase the economicity, the efficiency and the effectiveness in the use of public funds and that the SAI professionals also carried out actions for monitoring the recommendations implementation.

Cluster 4 includes 5\% of the total respondents. They have an average of 17 years of experience in the entities they represent; $75 \%$ of them consider that the performance audits have low utility; half consider that these missions bring, to a low extent, added value for increasing the economicity, the efficiency and the effectiveness in the activity of public sector entities; most of them consider that the themes and the objectives of the performance audits are not appropriate to the most important aspects of the entities' activity, that the SAI professionals made a relatively appropriate assessment of the factual situation regarding the economicity, the efficiency and the effectiveness with which the public resources are managed in order to achieve the set objectives and consider that the performance audit was mainly oriented towards the errors identification; half consider that the approach adopted by the external public auditors in the performance audit was not different from the approach in the financial or compliance auditing; the respondents grouped in this cluster stated that the relationship between the auditors and the audited entity staff was not felt to be different in the case of the performance audit compared to the financial or the compliance audit; they also stated that the recommendations for improving the activity had been made without consulting them; $75 \%$ of them stated that, following the performance audits, no changes were recommended at the level of the entities they represent; in the opinion of the majority of the respondents in this cluster, performance audits determined to a small extent the improvement of the management policies and practices, of the management internal control systems, of the own mechanisms for monitoring and evaluating performance, of the transparency regarding the way of managing public funds and of the financial-accounting activity accuracy and relatively the improvement of the accountability in the economic, effective and efficient use of the public funds; the respondents stated that the stakeholders perceptions did not change as a result of the performance audit report publication; most of them stated that the recommendations made were fully implemented; in all the cases, the SAI professionals also carried out actions for monitoring the recommendations implementation; according to the majority, the recommendations made following the performance audit missions had little contribution in the increase of the economicity, efficiency and effectiveness of the use of public funds at the entity level.

Regarding the investigation of the public management perception on the characteristics of the performance audit reports prepared by the Romanian SAI's professionals, the audited entities' representatives had the possibility to select several response options. The synthesis of the results obtained in this respect is presented in Figure 6. The most common quality of performance audit reports, disclosed by public management is objectivity, followed by fairness. The audited entities representatives also consider the audit reports to be complete, rigorously substantiated and credible. From a diametrically opposite perspective, 3 of the 
subjects appreciate them as formal. However, an aspect that we consider to be favorable concerns the fact that none of the respondents assessed the performance audit reports as deficient.

Figure 6. The characteristics of the performance audit reports

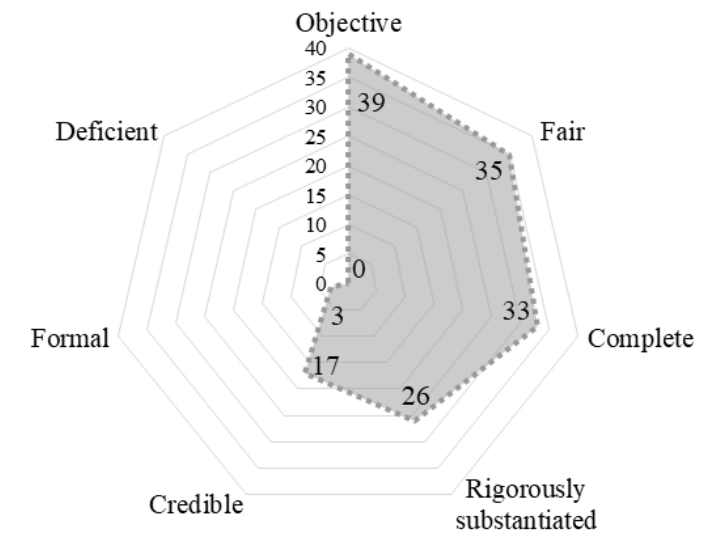

Subsequently, the respondents were asked to assess the extent to which the findings and the recommendations made within the performance audits, conducted by RCoA, contributed to "the 3E" (economicity, efficiency and effectiveness) and they were able to assess one, two or all the three aspects (Figure 7).

Figure 7. The extent to which the findings and the recommendations, made within the performance audits, contributed to "the $3 E$ "

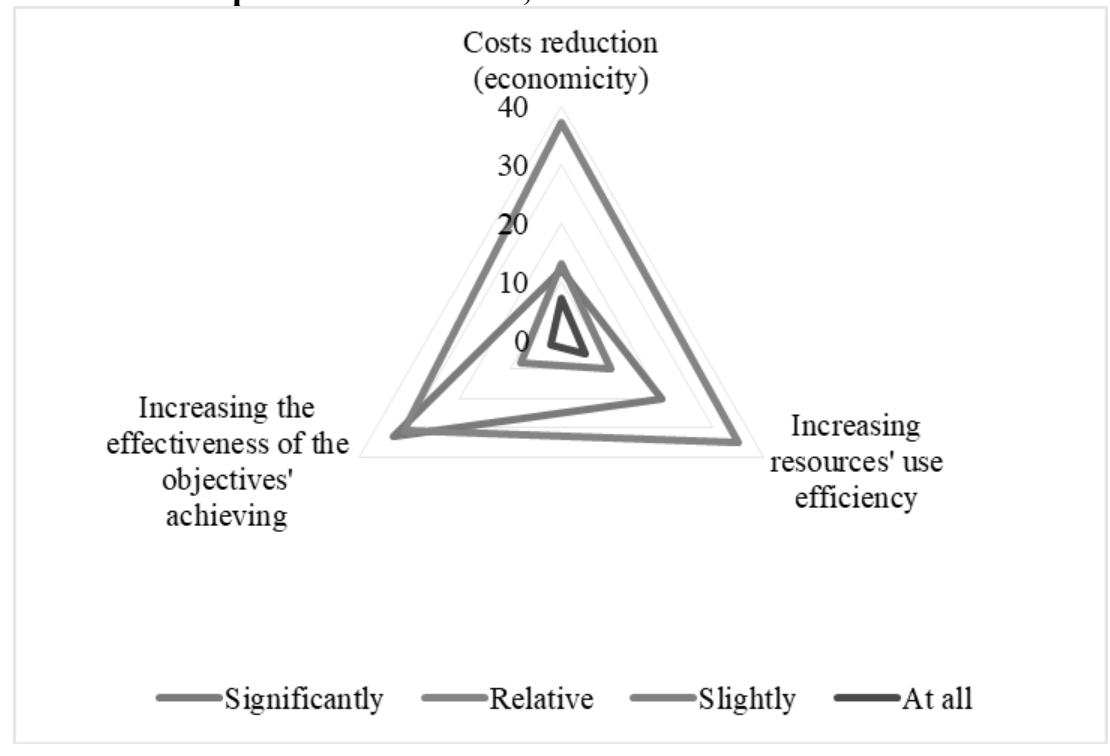

Vol. 19, No. 4 
Almost half of the respondents opined that the recommendations made subsequent to the performance audit missions, carried out by the Romanian SAI, contribute in a relative manner to costs reducing and to resource efficiency increasing and significantly to increasing the effectiveness of the objectives' achieving. At the same time, the percentage of respondents who believe that these findings and recommendations contribute to a small extent (on average 14\%) to the issues related to "the $3 \mathrm{E}$ " with regard to the audited elements or have a negative opinion on this (on average 6\%) should not be neglected.

Correlatively, when asked whether the RCoA's professionals also carried out followup actions on the recommendations' implementation, $84 \%$ of the audited entities' representatives responded affirmative. Through a filter question, they were asked to assess whether these follow-ups stimulated the recommendations' implementation at the entities. The results show that from the perspective of $71 \%$ of respondents, the follow-ups certainly stimulated the recommendations fulfilment at the performance audited entities, while $21 \%$ of respondents adopted a neutral opinion on this issue and $8 \%$ a negative opinion. The importance of monitoring the recommendations by the SAI's auditors is also supported by Umor et al. (2016), given the real quantification of the value generated by the performance audit.

Also, in relation to the ranking of four elements (on a scale of 1 to $4,1=$ the most important element and $4=$ the least important element), depending on the importance assessed by the respondents in ensuring the performance audit missions' success and effectiveness, the results of the research showed that for the majority of respondents, the most important element is the auditors' collaboration and communication with the entity, followed by the recommendations implementation follow-up, the auditors' proper understanding of the entity's field of activity and the auditors' experience, which makes possible to formulate the recommendations taking into account the best practices in the field.

Regarding the alternatives that could increase the value added from performance audit missions, the majority of respondents opted for the possibility of asking RCoA to carry out performance audits on specific areas of interest, which public management considers vulnerable, in order to obtain specific performance improvement recommendations. In the descending order of the respondents' preferences, the other options were to carry out periodic performance audits (as in the case of the financial audit), in order to assess periodically the economicity, efficiency and effectiveness with which public resources allocated to the entity are used to achieve the set objectives and to convert the recommendations into coercive measures when they are not carried out within a certain period. The positive impact of performance audits on the activity of public institutions was also validated by the results of the research conducted by Alwardat and Basheikh (2017). At the same time, regarding these alternatives, the respondents were free to add personal views, emphasizeing the importance of advice and guidance from RCoA's professionals 
and the need to harmonise the approaches, in the context in which in practice different approaches of the external public auditors have been reported in the same case. The respondents also pointed out some reluctance to the performance audit actions, which are perceived sometimes as control demarches more than analyses in support of audited entities.

\section{Conclusions}

The overall analysis of the research results highlights the importance that respondents give to the performance audits conducted by the Romanian SAI, argued by the value they add to public institutions activities, in terms of the resources' use and performance. Thus, the research results also confirm the important role of supreme audit institutions in ensuring public sector accountability (Cordery \& Hay, 2019).

A first result of the research reveals that the majority of respondents, who have an average experience within the entities they represent, attribute high utility to performance audits and consider that they bring, to a large or very large extent, added value regarding "the $3 \mathrm{E}$ " in the activity of the public sector entities, unlike the respondents with long experience at the level of the performance audited entities, which attribute medium or low utility to these approaches, and most adopt a neutral opinion on the added value they generate. From this perspective, the results are convergent with those of the research conducted by Yetano et al. (2019) at the level of public entities in Latin American countries, respectively Johnsen et al. (2019) at the level of public administration in the Nordic countries, on the usefulness of performance audits in the public sector. The research highlighted that most of the respondents consider that the themes and the objectives of the performance audits are appropriate to the most important aspects of the audited entities' activity and that the SAI's professionals correctly assessed the factual situation, providing a fair image of the economicity, efficiency and effectiveness with which the public resources are managed in order to achieve the set objectives.

Another result of the conducted research reveals that most of the respondents stated that performance audit missions focused equally on identifying errors and on evaluating performance. Also, from the perspective of the majority of respondents, the approach taken by the external public auditors in performance auditing compared to financial or compliance auditing was relatively different, but the relationship between the auditors and the staff of the audited entity was not felt to be different. Most of the respondents stated that they were involved in the process of identifying the best ways to improve the activity.

The research results showed that, most of the times, subsequent to the performance audits, changes were recommended at the level of the audited entities, but these were 
not significant. Such an approach was also supported by the results of the research conducted by Desmedt et al. (2017) at the level of the Belgian public administration.

Regarding the performance audits' objectives, the respondents consider that they are appropriate to the sensitive areas related to the public institutions' activity and their results provide a fair image of the public resources' management and use. Regarding the performance audit reports, the respondents consider them objective, rigorous, credible, and the collaboration and communication of the auditors with the entity are appreciated as successful elements of the performance audit mission. A high level of agreement among the management of the audited entities was identified regarding the extent to which stakeholders' perception changed as result of the performance audit report publication, most of them stating that this perception was not influenced. Although the SAI' recommendations were fully or partially implemented by the entities, they contributed to the economicity, efficiency and effectiveness increase in the use of public funds, and in most of the cases, the external public auditors also performed subsequent follow-up missions regarding the implementation of the advanced recommendations. Thus, by reference to the research conducted by Torres et al. (2019) on assessing the performance audits' impact in terms of formulating and implementing the recommendations of the SAIs within the European Union, the results of our research reveal that Romania applies the Anglo-American model. Regarding the potential alternatives for improving the value added through the performance audit missions, most of the respondents opted for the possibility to request RCoA to perform audits on specific areas of interest, that public management consider vulnerable, in order to obtain punctual recommendations for improving performance.

Regarding the research limits, we consider that they are related to certain barriers regarding the approach of the external public audit in the Romanian specialized literature, the low number of responses by reference to the number of disseminated questionnaires, correlative with the respondents' reluctance to disseminate information from within the entity or to express their perception of the subject.

An explanation of the low number of respondents is the socio-economic context in which the research took place, respectively the COVID-19 pandemic that generated the installation of the state of emergency in Romania and the radical change of the organization of human resources in the public sector. At the same time, we consider that the reluctance to participate to the undertaken study might be influenced by the management changes within the audited entities or by the respondents' daily activity volume. As future research directions, we intend to continue the investigative approach by extending the analysis regarding the impact and the effectiveness of the performance audits conducted by the supreme audit institutions, through a comparative study between the experience of Romania and that of another Member State of the European Union. We also consider the analysis of how the COVID-19 pandemic context has impacted on the supreme audit institutions activities. 


\section{References}

Alwardat, Y.A. \& Basheikh, A.M. (2017) "The impact of performance audit on public administrations in Saudi Arabia: an exploratory study", International Journal of Business and Management, vol. 12, no. 12: 144-157

Androniceanu, A. (2008) Noutăți în managementul public. Ediția a III-a [News in public management. 3rd Edition], București: Editura Universitară

Bartoli, A.(2009) Management dans les organizations publiques [Management in public organizations], Paris: Dunod

Bonollo, E. (2019) "Measuring supreme audit institutions? Outcomes: current literature and future insights", Public Money \& Management, vol. 39(7): 468-477

Bostan, I. \& Dascălu, E.D. (2016) "Strengthening the sustainability of public finances by means of financial law focused on the control and audit exercise", Ecoforum Journal, vol. 5, no. 1(8): 387-393

Cordery, C.J. \& Hay, D. (2019) "Supreme audit institutions and public value: demonstrating relevance", Financial Accountability \& Management, vol. 35(2): 128-142

Desmedt, E., Morin, D., Pattyn, V. \& Brans, M. (2017) "Impact of performance audit on the administration: a Belgian study (2005-2010)", Managerial Auditing Journal, vol. 32, no. 3: 251-275

Johnsen, A. (2019) "Public sector audit in contemporary society: a short review and introduction", Financial Accountability \& Management, vol. 35(2): 121-127

Johnsen, A., Reichborn-Kjennerud, K., Carrington, T., Jeppesen, K.K., Taro, K. \& Vakkuri, J. (2019) "Supreme audit institutions in a high-impact context: a comparative analysis of performance audit in four Nordic countries", Financial Accountability \& Management, vol. 35(2), 158-181

Marcu, N. (2018) "Principles and ethical values in public external audit activity. Current issues in corporate social responsibility", Springer International Publishing AG, pp. 185-194

Matei, L. (2006) Management public. Ediția a doua [Public management. Second edition], București: Editura Economică

Nișulescu, I. \& David Martin, M. (2009) "External audit. A parallel between the financial audit and the performance audit", Audit Financiar, vol. 7(4): $17-25$

Pitulice, C.I. \& Ștefănescu, A. (2016) "Research on the accurate image supplid by the financial reporting. The case of the local public administration entities form Romania", Proceedings of the 11th International Conference on Accounting and Management Information Systems (AMIS), 8-9 June 2016, Bucharest, pp. 450-462

Raudla, R., Taro, K, Agu, C. \& Douglas, J. (2016) "The impact of performance audit on public sector organizations: the case of Estonia", Public Organization Review, vol. 16: 217-233

Reichborn-Kjennerud, K. \& Johnsen, A. (2018) "Performance audits and supreme audit institutions' impact on public administration: the case of the Office of 
the Auditor General in Norway", Administration \& Society, vol. 50(10): $1422-1446$

Reichborn-Kjennerud, K. (2014) "Performance audit and the importance of the public debate", Evaluation, vol. 20(3): 368-385

Sembiyeva, L.M., Beisenova, L.Z. \& Alikulova, L.B. (2019) "Details of performance audit organisation in the Republic of Kazakhstan", News of the National Academy of Sciences of the Republic of Kazakhstan. Series of Social and Human Sciences, vol. 2, no. 324: 246 - 251

Slobodyanik, Y. (2019) "The contribution of supreme audit institutions to good governance and sustainable development: the case of Ukraine", Ekonomista, issue 4: 472-486

Svardsten, F. (2019) "The "front stage" of substance auditing: a study of how substance auditing is presented in performance audit reports", Financial Accountability \& Management, vol. 35(2): 199-211

Ştefan, L. \& Păunică, M. (2014) "Performance audit of resource utilization during the economic crisis", Ovidius University Annals, Economic Sciences Series, vol. XIV, no. 2: 585-590

Tiron-Tudor, A. (2007) "Performance audit in public sector entities - a new challenge for Eastern European countries", Transylvanian Review of Administrative Sciences, vol. 19E: 126-141

Torres, L., Yetano, A. \& Pina, V. (2019) "Are performance audits useful? A comparison of EU practices", Administration \& Society, vol. 51(3): 431-462

Trincu-Drăguşin, C.P. \& Ştefănescu, A. (2020) "The external public audit in the member states of the European Union: between standard typology and diversity", Audit Financiar, vol. XVIII, no. 3(159): 555-567

Umor, S., Zakaria, Z., Sulaiman, N.A. \& Kutty, R.M. (2018) "Preliminary insights: isomorphism and effectiveness of performance auditing issues follow-up", International Journal of Engineering \& Technology, vol. 7(4.28): 121-128

Umor, S., Zakaria, Z. \& Sulaiman, N.A. (2016) "Follow-up audit as an accountability mechanism of public sector performance auditing", 3rd International Conference on Accounting Studies (ICAS), 15-18 August 2016, Malaysia

Yetano, A., Torres, L. \& Castillejos-Suastegui, B. (2019) "Are Latin American performance audits leading to changes?", International Journal of Auditing, vol. 23(3): 444-456

*** The Regulation on the organization and conduct of the specific activities of the Court of Accounts, as well as the capitalization of the acts resulting from these activities, approved by the Plenum of the Court of Accounts by Decision no. 155/29 May 2014, published in the Official Gazette of Romania, Part I, no. 547 of July 24, 2014, with the subsequent amendments and completions

*** The Romanian Parliament, Law no. 94/1992 on the organization and functioning of the Romanian Court of Accounts, republished, with the subsequent amendments and completions 